\title{
Multiple peroxisome proliferator-activated receptor $\beta$ subtypes from Atlantic salmon (Salmo salar)
}

\author{
Michael J Leaver, M Tariq Ezaz, Stephanie Fontagne, Douglas R Tocher, \\ Evridiki Boukouvala ${ }^{1}$ and Grigorios Krey ${ }^{1}$
}

Institute of Aquaculture, University of Stirling, Stirling FK9 4LA, UK

${ }^{1}$ National Agricultural Research Foundation, Fisheries Research Institute, Nea Peramos, 64007 Kavala, Greece

(Requests for offprints should be addressed to M J Leaver; Email: mjl1@stir.ac.uk)

(M Tariq Ezaz is now at Research School of Biological Sciences, Australian National University, Canberra, Australian Capital Territory 0200, Australia)

(S Fontagne is now at INRA, 64310 Saint-Pee sur Nivelle, France)

\begin{abstract}
Peroxisome proliferator-activated receptors (PPARs) are ligand-activated transcription factors belonging to the nuclear hormone receptor superfamily that functions as critical regulators of lipid and energy homeostasis. Although intensively studied in mammals, their basic biological functions are still poorly understood. The objective of this work was to characterize PPAR $\beta$ subtypes in a fish, the Atlantic salmon (Salmo salar), in order to address PPAR function and the regulation of lipid homeostasis in lower vertebrates. The screening of an Atlantic salmon genomic library revealed the presence of four genes for PPAR $\beta$ subtypes. Based on comparisons of exons and exon-flanking regions, these genes were assigned into two families, ssPPAR $\beta 1$ and ssPPAR $\beta 2$, each family containing two isotypes: ssPPAR $\beta 1 A$ and $\beta 1 B$ and ssPPAR $\beta 2 A$ and $\beta 2 B$. Two full-length $c D N A$ s for ssPPAR $\beta 1 A$ and ssPPPAR $\beta 2 A$ were isolated. Transcripts for SSPPAR $\beta 1 A$ and sSPPARB2A have distinct tissue expression profiles, with ssPPAR $\beta 1 A$ predominating in liver and ssPPAR $32 A$ predominating in gill. Expression levels of mRNA of either isotypes were up to tenfold lower in kidney, heart, spleen, muscle, and brain. In cellular transfection assays, ssPPAR $\beta 1 A$ is activated by monounsaturated fatty acids, 2-bromopalmitate, and mammalian PPAR $\beta$-specific ligand GW501516. In contrast, PPARB2A was not activated by any of the compounds tested. Furthermore, ssPPAR $\beta 2 A$ repressed both the basal reporter gene activity and the GW501516induced activity of SsPPAR $\beta 1 A$. The results indicate unexpected levels of variety and complexity in PPAR subtype and mechanism of action in lower vertebrates.
\end{abstract}

Journal of Molecular Endocrinology (2007) 38, 391-400

\section{Introduction}

Peroxisome proliferator-activated receptors (PPARs) are ligand-activated transcription factors that belong to the nuclear hormone receptor superfamily. Originally isolated from humans, rodents, and amphibians, they are now widely accepted to be critical regulators of lipid and energy homeostasis (Isseman \& Green 1990, Krey et al. 1993, Desvergne \& Wahli 1999, Hihi et al. 2002). In mammals, one gene for each of the three PPAR subtypes, $\operatorname{PPAR} \alpha, \operatorname{PPAR} \beta$ (also known as PPAR $\delta$ ), and PPAR $\gamma$, is present (Michalik \& Wahli 1999). The role of PPAR $\alpha$ is hypothesized to be primarily in controlling the reversible induction of $\beta$-oxidation in specific tissues, especially liver, as a response to changing energy requirements and nutritional status. The evidence for this comes most directly from rodents, where PPAR $\alpha$ is expressed in cells with high catabolic rates of fatty acid oxidation, such as hepatocytes, cardiomyocytes, kidney proximal tubules, and intestinal mucosa (Escher et al. 2001). Indeed, PPAR $\alpha$-null mice are incapable of upregulating fatty acid oxidation during fasting (Kersten et al. 1999, Leone et al. 1999). In contrast, mammalian PPAR $\gamma$ is considered to play a critical role in fat accumulation, particularly in adipocytes and in lipidaccumulating macrophages (Rosen \& Speigelman 2001). The role of PPAR $\beta$ is less well understood. Various studies suggest that PPAR $\beta$ has a role in the global control of lipid homeostasis in mammals. It is moderately activated by a range of unsaturated fatty acids (Forman et al. 1997) and has a broad tissue expression profile (Escher et al. 2001). PPAR $\beta$-null mice show reduced adipose stores (Peters et al. 2000), which cannot be explained by adipose-specific PPAR $\beta$ deficiency (Barak et al. 2002, Wang et al. 2003). Furthermore, in the absence of the ligand, PPAR $\beta$ can act as a repressor of PPAR $\alpha$ and PPAR $\gamma$ action (Shi et al. 2002). Similarly, in the cell overexpression systems and in the absence of activating ligand, PPAR $\beta$ can downregulate the genes involved in the lipid and energy metabolism (Tachibana et al. 2005). Recently, highly specific and potent synthetic ligands for mammalian PPAR $\beta$ have been developed.

DOI: 10.1677/JME-06-0043 Online version via http://www.endocrinology-journals.org 
Treatment of animals with these compounds has demonstrated that ligand-activated PPAR $\beta$ directly controls lipid utilization through upregulation of genes involved in $\beta$-oxidation and energy uncoupling in various tissues (Dressel et al. 2003, Tanaka et al. 2003, Wang et al. 2003, Tachibana et al. 2005). In consequence, PPAR $\beta$ ligands can have beneficial effects in correcting dyslipodemic states in various animal disease models. Thus, PPAR $\beta$ ligands are now receiving considerable attention as potential pharmaceuticals for the treatment of a variety of human diseases associated with dyslipidemia (Desvergne et al. 2004).

In addition to functioning as a regulator of energy metabolism, PPAR $\beta$ has also been shown to have significant roles in the control of cellular proliferation and differentiation. Studies on PPAR $\beta$-null mice have indicated the PPAR $\beta$ functions in skin wound healing (Michalik et al. 2001), keratinocyte differentiation (Schmuth et al. 2002, Kim et al. 2006) in apoptosis (Di-Poi et al. 2002), and skin and colon carcinogenesis (Harman et al. 2004, Kim et al. 2004).

Despite these developments, bona fide endogenous ligands for PPAR $\beta$ have still not been conclusively defined and the precise role of PPAR $\beta$ in lipid and energy metabolism, and how this relates to PPAR $\beta$ function in cellular differentiation and proliferation, is not yet understood. The study of PPARs in lower vertebrates such as fish offers an opportunity to compare expression, define common ligands, and infer common functions across vertebrates, thus informing studies on PPARs in humans. Recently, a study on two members of a major fish clade, the Perciformes, reported the identification and characterization of homologs of PPAR $\alpha, \beta$, and $\gamma$ (Leaver et al. 2005). Comparison of these gene sequences with information from the pufferfish (Takifugu rubripides and Tetraodon nigroviridis, also Perciformes) genome-sequencing projects suggested that these fishes possessed a single PPAR $\beta$ gene and that they shared many of the features of their mammalian counterpart. However, examination of the zebrafish genome database indicated that there are two PPAR $\beta$ genes in this Cypriniform species. Consequently, the exact number of genes and/or the presence of distinct PPAR isoforms in fish are yet to be determined. Here, we show that multiple PPAR $\beta$ genes are present in Atlantic salmon, a commercially important member of a third major fish clade, the Salmoniformes. Two of these gene products are demonstrated to differ in tissue expression profile and transactivation properties.

\section{Materials and methods}

\section{Isolation of Atlantic salmon PPAR genes}

An Atlantic salmon genomic DNA library was constructed in $\lambda$ FIXII (Stratagene, La Jolla, CA, USA) from DNA isolated from blood from a single individual. This library was screened with a ${ }^{32} \mathrm{P}$-labeled DNA probe corresponding to the ligand-binding domain (LBD) of plaice (Pleuronectes platessa) PPAR $\beta$ (Leaver et al. 2005). Hybridizing clones were isolated, phage DNA purified, restriction digested, and subjected to Southern blot analysis using the plaice PPAR $\beta$ probe. Hybridizing restriction fragments were then subcloned to plasmid vectors and sequenced using an $\mathrm{ABI} 477$ autosequencer and BigDye sequencing reagents. Sequences were analyzed using Autoassembler software supplied by Applied Biosystems.

\section{Isolation of Atlantic salmon PPARB CDNAs}

Full-length cDNAs were isolated from total salmon liver RNA using reverse transcription, PCR, and RACE (SMART RACE system, BD Clontech, Oxford, UK). Gene-specific primers (P1, P2, and P3; Fig. 1 and Table 1) were directed to the regions immediately adjacent to PPAR $\beta$ termination codons predicted from genomic sequencing. These primers were combined in $5^{\prime}$-RACE PCRs with SMART liver cDNA and the SMART system universal primer. Further, RACE PCR was performed with primers synthesized to specific regions within the products arising from the first round of reactions. These primers ( $\mathrm{P} 4$ and $\mathrm{P} 5$; Fig. 1 and Table 1 ) were used in nested PCR procedures. Finally, full-length open reading frames for salmon PPAR $\beta$ cDNAs were obtained using both forward and reverse gene-specific primers (P1, P6, P7, and P8; Fig. 1 and Table 1), designed from consideration of the previously isolated RACE products. All products were ligated to Escherichia coli plasmid vectors and sequenced.

\section{Tissue expression}

Total RNA was isolated from tissues of three Atlantic salmon (average mass $=200 \mathrm{~g}$ ) using TriReagent (Sigma). For quantitative PCR (QPCR), $1 \mu \mathrm{g}$ total RNA was converted to cDNA using a blend of poly-dT

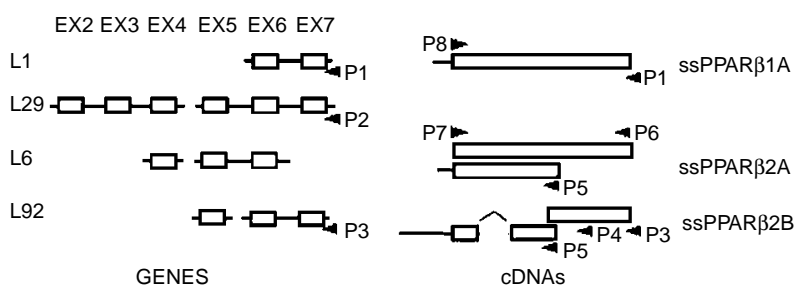

Figure 1 Schematic representation of Atlantic salmon PPAR $\beta$ genes and cDNAs. L1, L29, L6, and L92 are overlapping phage insert sets and the exons present are indicated as open boxes. ssPPAR $\beta 1 A, \beta 2 A$, and $\beta 2 B$ are the cDNAs isolated using the primers $\mathrm{P} 1-\mathrm{P} 8$ (see text), with the open reading frames indicated by open boxes. The ssPPAR $\beta 1 \mathrm{~B}$ cDNA corresponding to insert set L29 was not isolated. The diagram is not to scale. 
Table 1 Oligonucleotide primers used for Atlantic salmon PPAR $\beta$ cDNA isolation

Oligonucleotide $5^{\prime}$ to $3^{\prime}$

$\begin{array}{ll}\text { Primer } & \\ \text { P1 } & \text { TAAACCAGTCCAGTCAGTACATGTCC } \\ \text { P2 } & \text { CAGTCAGTACATGTCCTTATAGATC } \\ \text { P3 } & \text { TTCCAGTCAGTACAGATTTAGTCCGGT } \\ \text { P4 } & \text { CTTGGGGAAGACATAGAGGGAGTCCTG } \\ \text { P5 } & \text { TCGTTAAGGAAGAGATCCACAAACCCT } \\ \text { P6 } & \text { CAGGATCCATGGGTAGCCAACAGAATGGAGAGATTG } \\ \text { P7 } & \text { AAGGTACCAGTCAGTACATGTCCTTATAGATCTCCT } \\ \text { P8 } & \text { CTTGGATCCTGGGACATGAAG }\end{array}$

oligonucleotide primer ( $25 \mathrm{nM})$ and random hexamers (75 $\mathrm{nM}$ ), and Reverse-iT reverse transcriptase (AMV/ MMuLV blend; Abgene, Epsom, Surrey, UK). QPCRs of $20 \mu \mathrm{l}$ contained $100 \mathrm{nM}$ of each primer, $\mathrm{cDNA}$ from the equivalent of $25 \mathrm{ng}$ total RNA for PPAR $\beta$ reactions and from the equivalent of $0.25 \mathrm{ng}$ RNA for $18 \mathrm{~S}$ rRNA reactions. Amplicons were quantified using SYBR Green PCR mastermix (Abgene) and a Techne Quantica QPCR instrument. Cycling parameters consisted of a 15-min $95{ }^{\circ} \mathrm{C}$ soak to activate the polymerase, followed by 40 cycles of $95{ }^{\circ} \mathrm{C}$ for $15 \mathrm{~s}$ and $60{ }^{\circ} \mathrm{C}$ for $1 \mathrm{~min}$. Primers were directed to areas where the two cDNAs exhibited low nucleotide identity, either side of the junction corresponding to the first exon of the LBD of each PPAR. For ssPPAR $\beta 1 \mathrm{~A}$, these were 5'-GACCACCAACCCCAATGGCTCGGAT and 5'-CAGCCCATTCTCAGCCTGGCACAAG, and for ssPPAR $\beta 2 A, 5^{\prime}$-CCCCCACCATCT TGGTGGCTCAGA and 5'-TAGACCACTCTCTGCTTGCCACAGG. The PCR products produced from these primers under QPCR conditions were checked by gel electrophoresis and sequencing before undertaking QPCR. In each case, only the predicted products of 176 and $190 \mathrm{bp}$ for ssPPAR $\beta 1 \mathrm{~A}$ and ssPPAR $\beta 2 \mathrm{~A}$ respectively, were amplified. Values for PPAR $\beta$ were normalized to $18 \mathrm{~S}$ rRNA levels measured with primers 5'-CTGCCCTATCAACTTTCGATGGTACT and 5'-AA-AGTGTACTCATTCCAATTACGGGG.

\section{Cell transfection experiments}

Salmon PPAR $\beta$ cDNAs were ligated to pcDNA3 and used to transfect AS (derived from Atlantic salmon, epitheloid; Nicholson \& Byrne 1973) cells with pCMVßgal and a reporter construct containing a PPRE from the mouse cyp4A6 promoter (Ijpenberg et al. 1997) linked to a chloramphenicol acetyltransferase (CAT) gene. AS cells were routinely grown and passaged in Dulbecco's modified Eagle's medium (DMEM), 10\% fetal bovine serum (FBS). Prior to transfection, cells were passaged into DMEM, plus charcoal/dextran-stripped 10\% FBS (Pierce, Rockford, IL, USA). Total plasmid DNA $(1.5 \mu \mathrm{g})$ was transfected to each well of 12-well tissue culture plates using 7.5 $\mu$ Superfect reagent according to the manufacturer's instructions (Qiagen). Twentyfour hours after transfection, cells were treated with fatty acids $(100 \mu \mathrm{M}$; Sigma), Wy16463 $(50 \mu \mathrm{M})$, rosiglitazone, GW501516 $(10 \mu \mathrm{M}$; Alexis Corporation, Nottingham, UK), and L165041 (10 $\mu \mathrm{M}$; Calbiochem, Nottingham, UK) in $5 \mu \mathrm{l}$ ethanol. Cells were harvested $24 \mathrm{~h}$ after treatment, lysed in $300 \mu \mathrm{l}$ detergent-based buffer, and CAT protein was measured using an ELISA method (Roche). $\beta$-Galactosidase activity was measured in a microtitre plate-based assay. Briefly, $20 \mu \mathrm{l}$ cell lysate was incubated with $130 \mu \mathrm{l}$ PBS containing $5 \mathrm{mM} \mathrm{MgCl}_{2}$, $10 \mathrm{mM} \beta$-mercaptoethanol, and $1.5 \mathrm{mM}$ o-nitrophenyl$\beta$-galactoside (ONPG). After $30 \mathrm{~min}$, the reaction was stopped by the addition of $75 \mu \mathrm{l}$ of $1 \mathrm{M} \mathrm{Na}_{2} \mathrm{CO}_{3}$ and the $\mathrm{A}_{420}$ measured. CAT quantity was normalized to $\beta$-galactosidase activity and, after subtracting mocktransfected blank values, values for each treatment were expressed relative to the ethanol control for pcDNA3 (empty vector). All treatments were performed in triplicate.

\section{Results}

\section{Atlantic salmon possesses four distinct PPAR $\beta$ genes}

The salmon genomic library was screened with a probe corresponding to the LBD of a plaice PPAR $\beta$ (Leaver et al. 2005), and a total of nine distinct phage inserts were found to contain PPAR $\beta$-related sequences. Assembly of the sequences from these nine inserts produced four distinct clone sets, each comprised overlapping genomic fragments. Comparisons of exon sequences corresponding to the LBD of PPAR $\beta$ suggested that they contained distinct sequences. Based on the genomic sequence information, oligonucleotide primers were designed to be specific for each PPAR $\beta$ sequence. Initially, primers were directed to the regions adjacent to the termination codons of each of the three gene sequences (L1, L29, and L92 clone sets; Fig. 1). For the L1 clone set, a single cDNA was isolated (designated as ssPPAR $\beta 1 \mathrm{~A}$ ), which was found to contain a full-length open reading frame for PPAR $\beta$. For L92, a partial cDNA was obtained, containing only the coding region corresponding to the $\mathrm{LBD}$ of PPAR $\beta$. This cDNA was distinct from ssPPAR $\beta 1 \mathrm{~A}$. No PPAR $\beta$ cDNAs were obtained for the L29 clone set (designated as ssPPAR $\beta 1 B$ ). Using the partial cDNA sequence derived from the L92 clone set, two more oligonucleotides were designed to areas within the region corresponding to the LBD. These were used in a nested 5'-RACE procedure and two distinct cDNAs were obtained. One of these cDNAs contained an open reading frame for a PPAR $\beta$ isoform distinct from both ssPPAR $\beta 1 \mathrm{~A}$ and the partial L92 cDNA, and was 
designated ssPPAR $\beta 2 A$ (corresponding to the L6 clone set). The other cDNA corresponded, with $100 \%$ nucleotide identity in the overlapping region, to the previously isolated partial L92 cDNA. This cDNA contained an open reading frame, which lacked a DNA-binding domain but possessed an intact A/B domain and LBD, and together with the gene in the L92 clone set was designated ssPPAR $\beta 2 B$. The gene and cDNA sequences corresponding to the exons encoding the LBD of each of the presumed PPAR $\beta$ genes were aligned, together with exon-flanking regions (Fig. 2). The percentage identity matrices for these alignments showed that one of the cDNA sequences (ssPPAR $\beta 1 \mathrm{~A}$ ) was identical to the gene present in the L1 clone set. The other full-length cDNA (ssPPAR $\beta 2 A$ ) showed between 98 and $100 \%$ identity to clone set L6, whilst the atypical ssPPAR $\beta 2 B$ cDNA showed between 99 and $100 \%$ identity to the L92 clone set. Further attempts were made to isolate a cDNA (ssPPAR $\beta 1 \mathrm{~B})$ corresponding to the L29 genomic sequence from gill, kidney, and muscle cDNA, but were unsuccessful. It should be noted that the materials for the construction of genomic and cDNA libraries were derived from different individuals; thus, the small differences observed between these cDNAs and genes are most likely the result of allelic variation within salmon populations. In addition, apparent from the identity matrices, the clone sets fall into two groups of two genes each, with about $80 \%$ identity between the members from different groups. Exon-flanking sequences from the genes were compared to determine whether the four genes were from distinct loci, or were allelic variants from two loci. From Fig. 2, it is apparent that, although there is some similarity in the exon-flanking regions between L29 and L1, and between L6 and L92 clone sets, there is a lower level of identity than might be expected of allelic variants. This indicates that there are at least four distinct PPAR $\beta$ genes in salmon.

\section{Atlantic salmon PPAR $\beta$ phylogeny}

Comparison of the deduced amino acid sequences of the full-length ssPPAR $\beta 1 \mathrm{~A}$ and ssPPAR $\beta 2 \mathrm{~A}$ cDNAs clearly demonstrated that both salmon PPARs phylogenetically clustered with PPAR $\beta$ subtypes from diverse vertebrates (Fig. 3). The salmon PPARs were most closely related to PPARs from other fish species. However, it is notable that, within the PPAR $\beta$ phylogeny, the two zebrafish PPAR $\beta$ isoforms do not resolve on the same branches as the salmon isoforms, and in any case their positions in the phylogeny are not well supported by bootstrap values. Most amino acid identity between the salmon isoforms and PPAR $\beta$ from other vertebrates was evident in the DNA- and ligand-binding regions, although there were also areas of cross-species identity

\section{EXON 5}

\begin{tabular}{|c|c|c|c|c|c|c|c|c|}
\hline & B1A & 81A & $\begin{array}{l}\mathbf{2 9} \\
93.2\end{array}$ & $\begin{array}{l}\text { L6 } \\
80.7\end{array}$ & $\begin{array}{l}192 \\
79.2\end{array}$ & $\begin{array}{l}\text { B2A } \\
79.7\end{array}$ & $\begin{array}{l}\text { 82B } \\
78.7\end{array}$ & \\
\hline $\begin{array}{l}\text { TAACTARATACCCTCCCCCATAG } \\
\text { TTTCTCTCTCTCTCCCCCGGCAG } \\
\text { TTGCTTTCTCTCTGTCCCCTCAG }\end{array}$ & $\begin{array}{l}29 \\
L 6 \\
L 92\end{array}$ & $\begin{array}{l}93.2 \\
80.7 \\
79.2\end{array}$ & $\begin{array}{l}\overline{80.2} \\
78.7\end{array}$ & $\frac{80.2}{90.8}$ & $\begin{array}{l}78.7 \\
90.8 \\
\end{array}$ & $\begin{array}{l}79.7 \\
98.1 \\
91.3\end{array}$ & $\begin{array}{l}78.3 \\
90.3 \\
99.5\end{array}$ & $\begin{array}{l}\text { GTATATACAAGAACACACCAATT } \\
\text { GTATGGTATGGACCACGGTCTCC } \\
\text { GTACGGCACGGAGATAGAGATAT }\end{array}$ \\
\hline & $\begin{array}{l}\text { 82A } \\
\text { B2B }\end{array}$ & $\begin{array}{l}79.7 \\
78.7\end{array}$ & $\begin{array}{l}79.7 \\
78.3\end{array}$ & $\begin{array}{l}98.1 \\
90.3\end{array}$ & $\begin{array}{l}91.3 \\
99.5\end{array}$ & $\overline{90.8}$ & 90.8 & \\
\hline
\end{tabular}

\section{EXON 6}

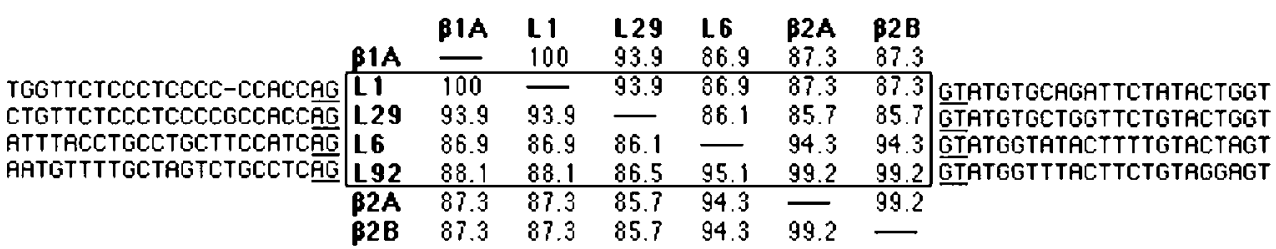

EXON 7

\begin{tabular}{|c|c|c|c|c|c|c|c|c|}
\hline & & B1A & L1 & $\mathbf{L 2 9}$ & $\mathbf{L 9 2}$ & $B 2 \mathrm{~A}$ & B2B & \\
\hline & B1A & 0 & & 94.8 & 82.3 & 82.3 & 82,3 & \\
\hline 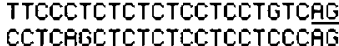 & L1 & $\begin{array}{l}100 \\
348\end{array}$ & 948 & 94.8 & $\begin{array}{l}82.3 \\
827\end{array}$ & 82.3 & 82.3 & $\begin{array}{l}\text { TGACTGGRCTGGTTTAGCTTCCT } \\
\text { TGACTGGACTGARTGGACCAGA }\end{array}$ \\
\hline AACTRTTCTCTATCCATCTGCAG & L92 & 82.3 & 82.3 & 82.7 & $\underline{0.18}$ & 100 & 100 & TGACTGGACCGGACTRARTCTGT \\
\hline & $\overline{\beta 2}$ & 82.3 & 82.3 & 82.7 & 100 & - & 100 & \\
\hline & B2I & 82.3 & 82.3 & 82.7 & 100 & 100 & - & \\
\hline
\end{tabular}

Figure 2 Identity matrices and exon-flanking regions of Atlantic salmon PPAR $\beta$ genes and cDNAs comprising the region corresponding to the ligand-binding domain. Numbers indicate the percentage identity between pairs of sequences. L1, L6, L29, and L92 are the gene sequences (boxed). The flanking exon sequences are shown with the AG/GT splice junctions and TGA termination codons underlined. $\beta 1 A$, $\beta 2 A$, and $\beta 2 B$ are the ssPPAR $\beta$ cDNA sequences. 


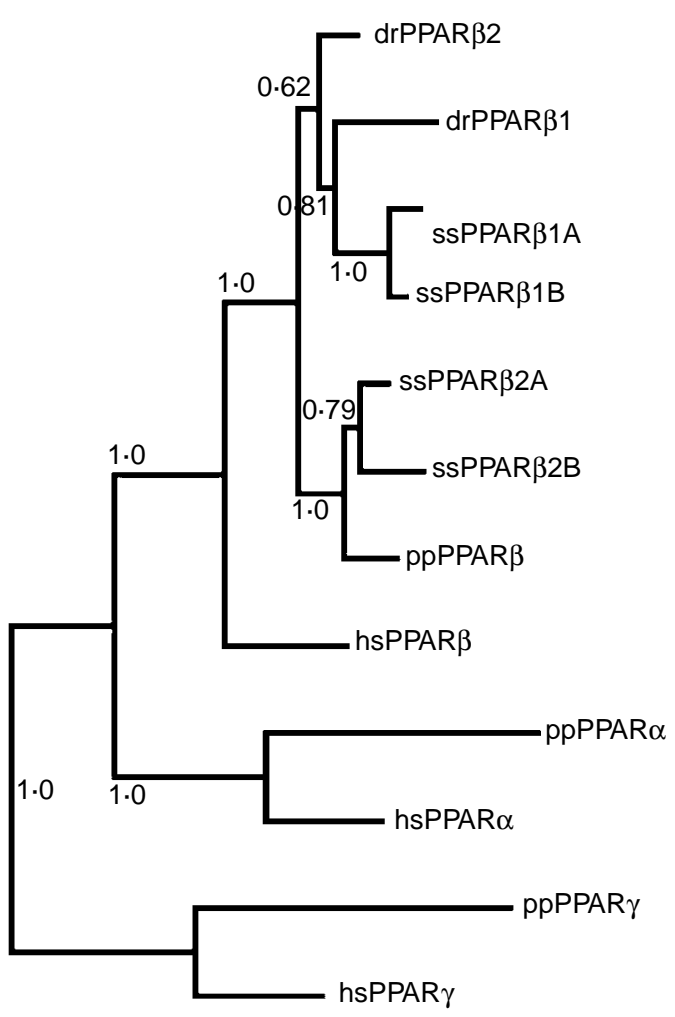

Figure 3 Phylogenetic tree for the ligand-binding domain (LBD) of PPARs from diverse species. The deduced amino acid sequences corresponding to the LBD of the PPAR isotypes from plaice (pp), Atlantic salmon (ss), human (hs), and zebrafish (dr) were aligned using ClustalW and the resulting data used to construct an unrooted tree using Bayesian inference (MrBayes 3; Ronquist \& Huelsenbeck 2005). The tree was plotted with NJplot. Confidence values of branch topologies are indicated.

in both the AB- and D-domains (Fig. 4). In both ssPPAR $\beta 1 \mathrm{~A}$ and ssPPAR $\beta 2 \mathrm{~A}$, the amino acid residues that interact with fatty acid ligand and co-activator proteins are conserved (Nolte et al. 1998, Xu et al. 1999, Fyffe et al. 2006, Fig. 4).

\section{Differential tissue expression of salmon PPAR $\beta$ genes}

QPCR analysis of salmon PPAR $\beta$ expression across a range of tissues indicated that there were differences in relative expression levels (Fig. 5). ssPPAR $\beta 1 \mathrm{~A}$ was most highly expressed in liver and adipose, whilst ssPPAR $\beta 2 \mathrm{~A}$ was most highly expressed in gill and adipose. The levels of ssPPAR $\beta 1 \mathrm{~A}$ exceeded those of ssPPAR $\beta 2 \mathrm{~A}$ in liver. In gill, ssPPAR $\beta 2 A$ was the predominant isoform and both were expressed equally in adipose. The expression levels in other tissues were three- to fivefold lower than in liver, gill, and adipose, and there were no differences between the expression level of ssPPAR $\beta 1 \mathrm{~A}$ and ssPPAR $\beta 2 A$.

\section{Differential transactivation of salmon PPAR $\beta$ subtypes}

In cellular transfection assays (Fig. 6), there was a relatively small but significant activation of ssPPAR $\beta 1 \mathrm{~A}$ by palmitoleic acid. In contrast, there was no apparent effect of oleic, linolenic, arachidonic, eicosapentenoic, or docosahexaenoic acids. There was a much greater response to the mammalian PPAR $\beta$-specific ligand GW501516 and bromopalmitate. However, L165041, another mammalian PPAR $\beta$-selective ligand, was not an effective activator of salmon ssPPAR $\beta 1 A$. Note that all compounds that resulted in the activation of ssPPAR $\beta 1 \mathrm{~A}$ also induced the basal activity of the reporter construct, suggesting the presence of endogenous ssPPAR $\beta 1 A$. Indeed, QPCR indicated that ssPPAR $\beta 1 A$ was present (not shown) in the AS cell line although at lower levels per unit input RNA than any of the salmon tissues tested. This may indicate that fatty acids are effective activators of ssPPAR $\beta 1 \mathrm{~A}$, since they all induced reporter gene activity significantly above that induced by the vehicle ethanol. Transfection of the ssPPAR $\beta 2$ A significantly reduced the basal level of transcription from the reporter construct with all tested compounds (Fig. 6), suggesting repression of endogenous ssPPAR $\beta 1 \mathrm{~A}$ activity in the AS cell line. To test this, AS cells were transfected with both ssPPAR $\beta A 1$ and ssPPAR $\beta 2 A$, and reporter gene activation measured after GW501516 treatment. The results confirmed (Fig. 7) that ssPPAR $\beta 2 A$ repressed both the basal and the GW501516-induced activity of ssPPAR $\beta 1 \mathrm{~A}$, as well as the endogenous basal and induced activity.

\section{Discussion}

Atlantic salmon are both a declining wild species with a complex and characteristic life cycle and a commercially valuable farmed species. The management of both wild and farmed stocks is as rich in social, economic, and political issues as its resource base is rich biologically. However, a particular biological problem which concerns both the survival of wild fish and the quality of farmed fish is related to the control of energy and, particularly, lipid homeostasis. PPARs are now known to be critical regulators of these processes. The study presented here is the first report of the functional characterization of PPAR subtypes from a salmonid species, the Atlantic salmon. Phylogenetic analysis shows that all the four genes described here belong to the PPAR $\beta$ subfamily. In mammals, where PPARs have been studied most intensively, a single gene encodes for PPAR $\beta$, and studies in other fish species have identified varying numbers of PPAR $\beta$ subtypes. BLAST searches of near complete genome sequences for the pufferfishes, Takifugu rubripes and Tetraodon 
hSPPAR $\beta$ MEQPQEEAPEVREEEEKEEVAEAEGAPELNGGPQHALPSSSYTDLSRSSSPPSLLDQLQM PPPPAR $\beta$ KKKRVPVSKGLKGDQKSKEKEHLDQEKNNHSKQKSSGASS. YTDLSHTSSP. SLSEQLRL SSPPARß1A ... MKSHDEEVVQQEQEDQQEKGNSNSHSTSNTDSPALSSSCTDLSQTSSP. SLSDQLLL SSPPAR $\beta 2 A$.....MCSQQNGENGGGEEERLEKDKTSYSRQDSPATDDNYTDLSHTSSP. SLSEQLRL

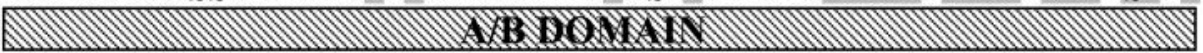

hSPPAR $\beta$ GCDGASCGSLNMECRVCGDKASGFHYGVHACEGCKGFFRRTIRMKLEYEKCERSCKIQKK pPPPAR $\beta$ GREDSTGAGISVECKVCGDKASGFHYGVHACEGCKGFFRRTVRMKLEYDRCERSCKILKK SSPPAR 1 IA GREDVTGAGINVECRICGDKASGFHYGVHACEGCKGFFRRTIRMKLEYERCERSCKIQKK SSPPAR $\beta 2 A$ GRDEVTGPGINVECRICADKASGFHYGVHACEGCKGFFRRTIRMKLEYERCERACKILKK

DNA BINDING DOMAIN

hSPPAR $\beta \quad$ NRNKCQYCRFQKCLALGMSHNAIRFGRMPEAEKRKLVAGLTANEGSQYN. PQVADLKAFS PPPPAR $\beta$ NRNKCQYCRFQKCLSLGMSHDAIRYGRMPEAERKKLVAGLLAEELTVSK. PGGSDLKTLA SSPPAR 11 A SRNKCQYCRFQKCLLLGMSHDAIRYGRMPEAEKRKLVAGLLAGERAPTTNPNGSDLKSLA SSPPARß2A NRNKCQYCRFQKCLALGMPHDAIRYGRMPGAEKKKLVAGLLAEELDPHH. LGGSDLKTLA

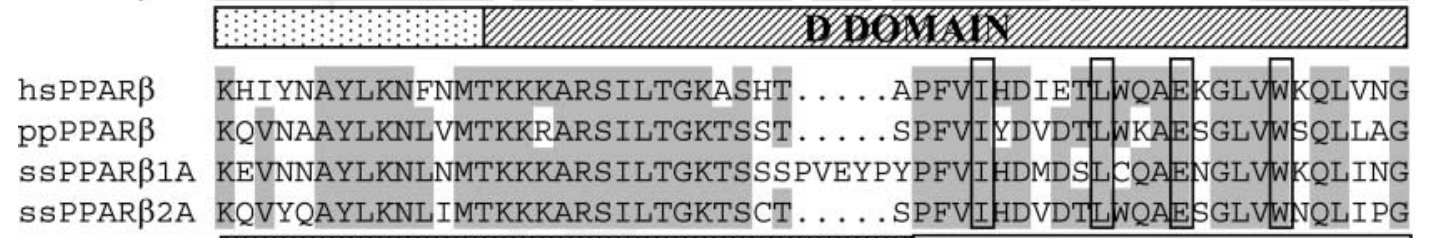

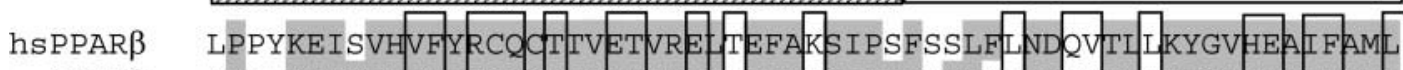

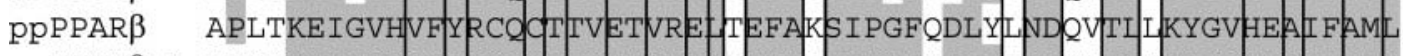
SSPPARß1A TTPNKEIGVHVF YRCO CT TVETVRE T EFA KS I PGFVDLF LNDVVITI IKYGV HEA I FAML SSPPARß2A APLTKVIGVHVFYRCOCITVETVRELTEFAKNI PGFVDLFLNDEVTILLKHGVHEA I FAML

hSPPAR ASIVNKDGEIVANGSGFVTREFIRSLRKPFSDI IEPKFEFAVKFNALELDDSDLALFIAA PPPPAR $\beta$ PSLMNKDGLLVANGKGFVIREFIRSLRKPFSEIMEPKFEFAVKFNALELDDSDLALFVAA SSPPAR $\beta 1 A$ PSLMINKDGLEVAN GKGFVVREFIRSLRRPFSE IMEPKFEFAVKFNALELDDSDLALFVAA SSPPARß2A PSLMNKDGLUVANGKGEVVREELRSLRKPFSEIMEPKFEFAVKFNSLELDDSDLALFVAA

\section{LIGAND BINDING DOMAIN}

hSPPAR $\beta$ IILCGDRPGLMNVPRVEAIQDTILRALEFHLQANHPDAQYLFPKLLQKMADLRQLVTEHA pPPPAR $\beta$ IILCGDRPGLMNVKQVEQSQDNILQALDLHLQANHSDSLYLFPKLLQKMADLRQLVT $N N A$ SSPPARß1A IILCGDRPGLINIKQVEEIQDSILQALDQHLLANHTDSKYLFPKLLNKMADLRQLVT ANA SSPPARß2A IILCGDRPGLMNVKQVEQSQDCILQALDLHLQANHODSLYVFPKLLNKMADLRQLVTENA

hSPPAR $\beta$ QMMORIKKTETETSLHALTELYKDMY PPPPAR $\beta$ LIVUKIKKTESETSLHA ITEEYY PDMY SSPPARß1A MIVVKIKKTESETSLHH I REIYKDMY SSPPARß2A LIVUKIKKTESEISLHHLLEIYKDMY

Figure 4 Comparison of PPAR $\beta$ from Atlantic salmon, plaice, and human. Alignment was generated with ClustalW, and identical residues present in three or more of the four sequences are shaded. The functional domains of the proteins are indicated by shaded or unshaded labeled boxes below the sequence line. The positions of residues which are not conserved in SSPPAR $\beta 2 A$ are highlighted. Residues involved in human PPAR $\beta$ ligand binding are boxed and shaded. Residues involved in human PPAR co-activator binding are boxed and unshaded. 


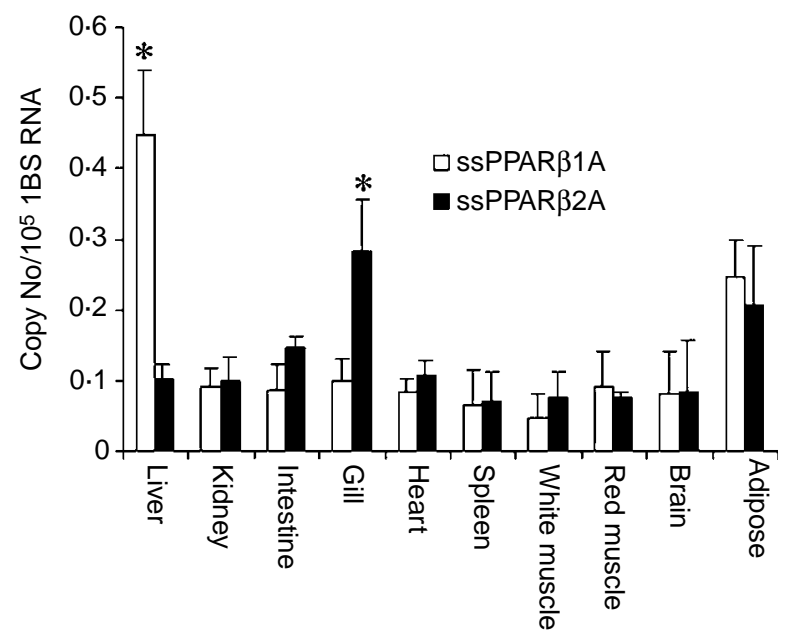

Figure 5 Tissue expression profile of Atlantic salmon PPAR $\beta$ isotypes. Results of QPCR assays as described in text. Data represent the mean \pm s.D. from three individual salmon. PPAR $\beta$ was normalized to $18 \mathrm{~S}$ RNA. Both genes were quantified by comparison with a standard curve of linearized plasmid containing the corresponding insert cDNA. Asterisks indicate tissues in which one of the PPAR subtypes significantly $(P<0.05$; $t$-test $)$ differs from the other.

nigroviridis, reveal the presence of only one PPAR $\beta$ gene. Similarly, in plaice and sea bream, it has previously been reported that only one PPAR $\beta$ gene is detectable (Leaver et al. 2005). This compares with the situation in zebrafish, where, from genomic sequence

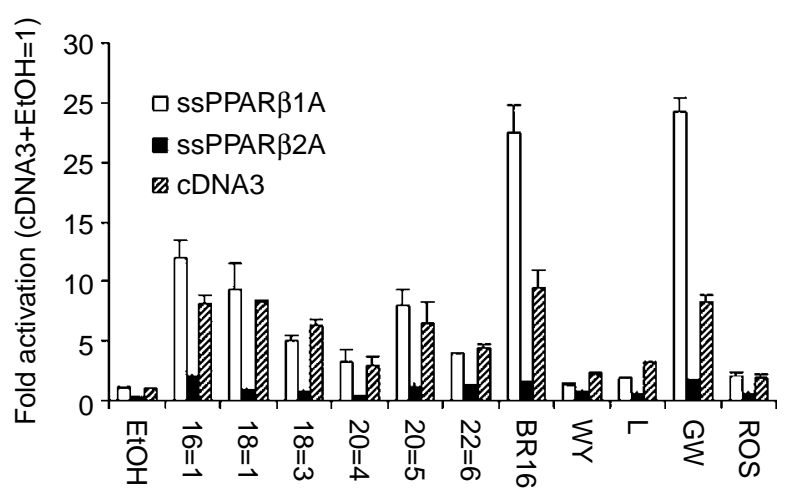

Figure 6 Transactivation of Atlantic salmon PPAR $\beta$. AS cells were transfected with the expression vector pcDNA3, alone (cDNA3) or containing the coding sequences for the two Atlantic salmon PPARs, a CAT reporter construct containing the Cyp4A6-Z PPRE and a $\beta$-galactosidase expression plasmid. Cells were treated with $100 \mu \mathrm{M}$ palmitoleic acid $(16=1)$, oleic acid $(18=1)$, linolenic acid $(18=3)$, arachidonic acid $(20=4)$, eicosapentenoic acid $(20=5)$, docosahexaenoic acid $(22=6), 50 \mu \mathrm{M}$ 2-bromopalmitate (BR16). $50 \mu \mathrm{M}$ Wy-14,643 (WY), $10 \mu \mathrm{M}$ L165041 (L), $10 \mu \mathrm{M}$ GW501516 $(\mathrm{GW})$, and $10 \mu \mathrm{M}$ rosiglitazone (ROS) or the vehicle ethanol (EtOH). Results are expressed as the fold increase in CAT (after subtraction of mock-transfected background and normalization to $\beta$-galactosidase) with respect to the ethanol control values for empty vector (pcDNA3). Figures represent a single experiment out of two repetitions and all treatments were in triplicate. Error bars correspond to mean \pm s.D.

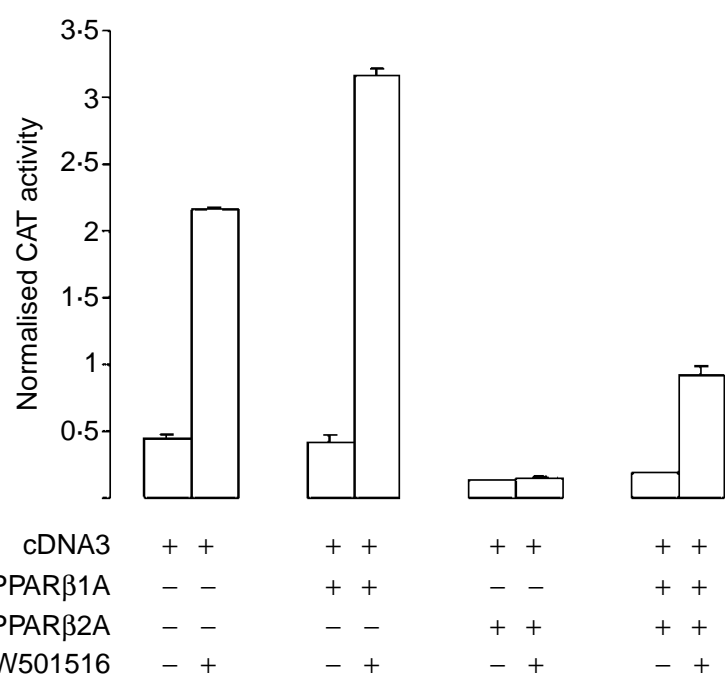

Figure 7 ssPPAR $\beta 2 A$ represses the activity of ssPPAR $\beta 1 A$. AS cells were transfected with cDNA3 (no PPAR) alone, or in combination with ssPPAR $\beta 1 A$ and/or ssPPAR $\beta 2 A$. Cells were treated with GW501516 or with the vehicle, ethanol, as indicated. Results are expressed as arbitrary units of normalized CAT activity. Figures represent a single experiment out of two repetitions and all treatments were in triplicate. Error bars correspond to mean \pm S.D.

and published information, there is clear evidence of two PPAR $\beta$ isoforms (Robinson-Rechavi et al. 2001, Leaver et al. 2005). Of the four Atlantic salmon sequences identified here, at least two appear to be functional genes for PPAR $\beta$ (termed here ssPPAR $\beta 1 A$ and ssPPAR $\beta 2 A$ ), as shown by the identification of corresponding cDNAs containing complete coding sequence. It is not clear whether our failure to isolate fully resolved cDNAs for the other two gene sequences is because these are not functional genes or because they are not expressed. It is nevertheless important to note that for one of the other genes (ssPPAR $\beta 2 B$ ), we were able to isolate a cDNA with an open reading frame containing an AB-domain, a D-domain, and a ligandbinding domain, but lacking a DNA-binding domain. It is not yet clear whether this represents an aberrantly or partially processed mRNA or codes for an atypical but functional PPAR $\beta$ subtype. For the other gene (ssPPAR $\beta 1 B)$, through sequence homology, we could identify six out of seven coding exons on a single lambda genomic clone (not shown; Accession numbers AM229298 and AM229299). The first coding exon of ssPPAR $\beta 1 B$ could not be definitively established because of the uncertainty in predicting this less conserved region of the gene by homology. Nevertheless, it is likely that this gene also encodes a functional PPAR. Attempts to isolate a cDNA for this gene from a variety of tissues were not successful, suggesting that it is either not expressed or is expressed in a tissue or developmentally restricted manner. 
The presence of four PPAR $\beta$ genes in salmonids is most probably a result of a relatively recent polyploidization event (60-90 million years), which is clearly evident in the evolution of salmonids (Allendorf \& Thorgaard 1984). Moreover, more ancient polyploidization events have been proposed as a driving force for the evolution of the vertebrate lineage (Ohno 1970). One of these has been proposed to have occurred in the early evolution of ray-finned fishes (Taylor et al. 2003) and recent comparative syntenic analyses of zebrafish and pufferfish genomes (Woods et al. 2005) have supported this event and inferred subsequent lineagespecific duplications or losses to account for the differences in gene numbers between these species. The four PPAR $\beta$ genes in Atlantic salmon clearly group into two subfamilies most likely representing the polyploidization-dependent duplication of two PPAR $\beta$ subtypes from an ancestral diploid salmonid, these two genes arising from the more ancient ray-finned fish event. The phylogenetic analysis suggests that these two salmon subfamilies are not orthologous to the two PPAR $\beta$ subtypes in zebrafish, although it should be noted that the zebrafish sequences are not placed in the tree with high confidence and a definitive conclusion must await functional characterization of the zebrafish PPAR $\beta$ subtypes.

From an evolutionary perspective, a key question surrounding the process of polyploidizaton is how an individual with a polyploid genome would gain a selective advantage in a population and thence give rise to a new polyploid species. For such polyploidized individuals to reproduce successfully, they are required to undergo a process of diploidization concurrent with functional divergence of duplicated loci to obtain a selective advantage over their diploid relatives (Wolfe 2001). The genetic divergence of PPAR $\beta$ subtypes in salmon may be an example of the outcome of this diploidization process, and as such these genes would be expected to exhibit functional divergence. Indeed, our results indicate that ssPPAR $\beta 1 \mathrm{~A}$ or ssPPAR $\beta 2 \mathrm{~A}$ are differentially expressed and exhibit distinct activation characteristics. Levels of ssPPAR $\beta 1 \mathrm{~A}$ predominate in liver and ssPPAR $\beta 2 A$ predominate in gill and the differential expression of salmon PPAR $\beta$ isoforms has functional significance when the cellular transfection results are considered. It would appear that ssPPAR $\beta 1 \mathrm{~A}$ is similar in ligand-activation profile to PPAR $\beta$ from other species (Forman et al. 1997, Oliver et al. 2001, Leaver et al. 2005) being responsive to palmitoleic and oleic acids and to 2-bromopalmitate. Importantly, it is highly activated by the mammalian PPAR $\beta$-selective ligand GW501516, but not activated by the PPAR $\alpha$ specific ligand WY146463. The response to GW501516 suggests that, as with PPAR $\beta$ in mammals, this compound is a ligand for ssPPAR $\beta 1 \mathrm{~A}$. The identification of highly selective and potent ligands for fish
PPARs is a necessary step in advancing understanding in this area and further studies are required to test whether GW501516 will be as selective and potent in salmon as it is in mammals. On the other hand, the lack of response of ssPPAR $\beta 2 A$ to fatty acids or PPAR $\beta$ selective ligands is intriguing. Consideration of the LBD of ssPPAR $\beta 2 A$ suggests that this may be because there are critical differences between the sequence of this isoform and the sequences of mammalian or other characterized fish PPAR $\beta$ homologs. A number of amino acid residues are not conserved in the ssPPARß2A subtype (Fig. 4), which may change the characteristics of the LBD. However, none of these substitutions are at positions shown to be involved in either fatty acid ligand binding (Xu et al. 1999, Fyffe et al. 2006) or co-activator binding to human PPAR (Nolte et al. 1998), suggesting that ssPPAR $\beta 2 A$ may be capable of binding and being activated by as yet undiscovered ligands. It is possible that, if the two salmon subtypes have conserved functions and binding specificity, the true endogenous ligand for vertebrate PPAR $\beta$ may not be fatty acids, but might in future be identified as a compound which activates both ssPPAR $\beta 1 A$ and ssPPAR $\beta 2 A$. Alternatively, the nonconserved substitutions or other characteristics of ssPPAR $\beta 2 A$ may prohibit ligand activation under any circumstances and its sole function may be to repress the activity of other PPARs. Mammalian PPAR $\beta$ has been shown to repress the activity of the other PPAR subtypes by competing for binding to PPREs (Shi et al. 2002). In this respect, the repressive ability of ssPPARß2A in both basal and GW501516-induced transcriptional activity is significant. The high levels of expression of ssPPAR $\beta 2 A$ in gill, in combination with its repressive activity, may have specific implications for the action of other PPAR subtypes in this tissue. As the fish gill is in close contact with the external environment, a single layer of epithelial cells separating the blood from the water, it is possible that in this tissue ssPPAR $\beta 2 \mathrm{~A}$ functions to repress the activity of other PPARs in order to prevent their un-programmed activation by exogenous compounds or contaminants. Thus, Atlantic salmon may have evolved novel PPAR $\beta$-dependent processes. In this regard, it is important to note that other salmonids, such as rainbow trout and brown trout (Onchorhyncus mykiss and Salmo trutta), are also polyploid and would thus contain homologs of the four salmon PPAR $\beta$ genes. Previous studies (Batisto-Pinto et al. 2005, Lui et al. 2005) of tissue expression profiles and PPAR-agonist responses in these species have considered only a single PPAR $\beta$ subtype identified from partial cDNA sequences. In future, and in the light of these results from salmon, such studies should be conducted with the expectation of the presence of multiple PPAR subtypes with divergent function in trout and other salmonids. 
In conclusion, these studies demonstrate the possibility for unexpected levels of variety in PPAR $\beta$ subtype and mechanism of action in Atlantic salmon, showing that further complexity in physiological control may result from functional divergence of duplicated nuclear receptor genes. Further studies are required to understand the role of these important regulators of lipid homeostasis in life cycle and evolutionary adaptation in salmonids and to determine common PPAR-dependent processes across all vertebrates.

\section{Acknowledgements}

This work was supported by a European Union research grant Q5RS-CT-2000-30360 and by the BBSRC, UK. Stephanie Fontagne was funded as a traveling fellow by the French Government. The sequences referred to have been deposited in the EMBL/NCBI databases under Accession numbers AM229297-AM229306. The authors declare that there is no conflict of interest that would prejudice the impartiality of this scientific work.

\section{References}

Allendorf FW \& Thorgaard GH 1984 Tetraploidy and the evolution of salmonid fishes. In Evolutionary Genetics of Salmonid Fishes, pp 1-53. Ed BJ Turner. New York: Plenum Press.

Barak Y, Liao D, He WM, Ong ES, Nelson MC, Olefsky JM, Boland R \& Evans RM 2002 Effects of peroxisome proliferator-activated receptor delta on placentation, adiposity, and colorectal cancer. PNAS 99 303-308.

Batisto-Pinto C, Rodrigues P, Rocha E \& Lobo-da-Cunha A 2005 Identification and organ expression of peroxisome proliferator activated receptors in brown trout (Salmo trutta f. fario). Biochimica et Biophysica Acta 1731 88-94.

Desvergne B \& Wahli W 1999 Peroxisome proliferator-activated receptors: nuclear control of metabolism. Endocrine Reviews 20 649-688.

Desvergne B, Michalik L \& Wahli W 2004 Be fit or be sick: peroxisome proliferator-activated receptors are down the road. Molecular Endocrinology 18 1321-1322.

Di-Poi N, Tan NS, Michalik L, Wahli W \& Desvergne B 2002 Antiapoptotic role of PPARb in keratinocytes via transcriptional control of the Aktl signaling pathway. Molecular Cell 10 721-733.

Dressel U, Allen TL, Pippal JB, Rohde PR, Lau P \& Muscat GE 2003 The peroxisome proliferator-activated receptor $\beta$ /agonist, GW501516, regulates the expression of genes involved in lipid catabolism and energy uncoupling in skeletal muscle cells. Molecular Endocrinology 17 2477-2493.

Escher P, Braissant O, Basu-Modak S, Michalik L, Wahli W \& Desvergne B 2001 Rat PPARs; quantitative analysis in adult rat tissues and regulation in fasting and refeeding. Endocrinology 142 4195-4202.

Forman BM, Chen J \& Evans RM 1997 Hypolipidemic drugs, polyunsaturated fatty acids, and eicosanoids are ligands for peroxisome proliferator-activated receptors $\alpha$ and $\delta$. PNAS 94 4312-4317.

Fyffe SA, Alphey MS, Buetow L, Smith TK, Ferguson MAJ, Sorenson MD, Bjorkling F \& Hunter WN 2006 Recombinant human PPAR$\beta / \delta$ ligand-binding domain is locked in an activated conformation by endogenous fatty acids. Journal of Molecular Biology 356 $1005-1013$.
Harman FS, Nicol CJ, Marin HE, Ward JM, Gonzalez FJ \& Peters JM 2004 Peroxisome proliferator-activated receptor-delta attenuates colon carcinogenesis. Natural Medicine 10 481-483.

Hihi AK, Michalik L \& Wahli W 2002 PPARs: transcriptional effectors of fatty acids and their derivatives. Cellular and Molecular Life Sciences 59 790-798.

Ijpenberg A, Jeannin E, Wahli W \& Desvergne B 1997 Polarity and specific sequence requirements of peroxisome proliferator-activated receptor (PPAR)/retinoid X receptor (RXR) heterodimer binding to DNA. A functional analysis of the malic enzyme gene PPAR response element. Journal of Biological Chemistry 274 15901-20117.

Isseman I \& Green S 1990 Activation of a member of the steroid hormone receptor superfamily by peroxisome proliferators. Nature $347645-650$

Kersten S, Seydoux J, Peters JM, Gonzalez FJ, Desvergne B \& Wahli W 1999 Peroxisome proliferator-activated receptor $\alpha$ mediates the adaptive response to fasting. Journal of Clinical Investigation 103 $1489-1498$.

Kim DJ, Akiyama TE, Harman FS, Burns AM, Shan W, Ward JM, Kennett MJ, Gonzalez FJ \& Peters JM 2004 Peroxisome proliferatoractivated receptor beta (delta)-dependent regulation of ubiquitin $\mathrm{C}$ expression contributes to attenuation of skin carcinogenesis. Journal of Biological Chemistry 279 23719-23727.

Kim DJ, Bility MT, Billin AN, Willson TM, Gonzalez FJ \& Peters JM 2006 $\mathrm{PPAR} \beta / \delta$ selectivity induces differentiation and inhibits cell proliferation. Cell Death and Differentiation 13 53-60.

Krey G, Keller H, Mahfoudi A, Medin J, Ozato K, Dreyer C \& Wahli W 1993 Xenopus peroxisome proliferator activated receptors: genomic organisation, response element recognition, heterodimer formation with retinoid $\mathrm{X}$ receptor and activation by fatty acids. Journal of Steroid Biochemistry and Molecular Biology 47 65-73.

Leaver MJ, Boukouvala E, Antonopoulou E, Diez A, Favre-Krey L, Ezaz MT, Bautista JM, Tocher DR \& Krey G 2005 Three peroxisomal proliferator-activated receptor (PPAR) isotypes from each of two species of marine fish. Endocrinology 146 3150-3162.

Leone TC, Weinheimer CJ \& Kelly DP 1999 A critical role for the peroxisome proliferators-activated receptor $\alpha(\operatorname{PPAR} \alpha)$ in the cellular fasting response: the PPAR $\alpha$-null mouse as a model of fatty acid oxidation disorders. PNAS 96 7473-7478.

Lui GL, Moon TW, Metcalfe CD, Lee LEJ \& Trudeau VL 2005 A teleost in vitro reporter gene assay to screen for agonists of the peroxisome proliferators-activated receptors. Environmental Toxicology and Chemistry 24 2260-2266.

Michalik M \& Wahli W 1999 Peroxisomal proliferator-activated receptors: three isotypes for a multitude of functions. Current Opinion in Biotechnology 10 564-570.

Michalik L, Desvergne B, Tan NS, Basu-Modak S, Escher P, Rieusset J, Peters JM, Kaya G, Gonzalez FJ, Zakany J et al. 2001 Impaired skin wound healing in peroxisome proliferator-activated receptor (PPAR)alpha and PPARbeta mutant mice. Journal of Cell Biology 154 799-814.

Nicholson BL \& Byrne C 1973 An established cell line from Atlantic salmon (Salmo salar). Journal of the Fisheries Research Board of Canada 30 916-923.

Nolte RT, Wisely GB, Westin S, Cobb JE, Lambert MH, Kurokawa R, Rosenfeld MG, Willson TM, Glass CK \& Millburn MV 1998 Ligand binding and co-activator assembly of the peroxisome proliferatoractivated receptor-gamma. Nature 395 137-143.

Ohno S 1970. Evolution by Gene Duplication. London: George Allen and Unwin.

Oliver WR Jr, Snaith MR, Russell CS, Plunket KD, Bodkin NL, Lewis MC, Winegar DA, Sznaidman ML, Lambert MH, Xu HE et al. 2001 A selective peroxisome proliferator-activated receptor $\delta$ agonist promotes reverse cholesterol transport. PNAS 98 5306-5311.

Peters JM, Lee SS, Li W, Ward JM, Gavrilova O, Everett C, Reitman ML, Hudson LD \& Gonzalez FJ 2000 Growth, adipose, brain and skin 
alterations resulting from targeted disruption of the mouse peroxisome proliferator-activated receptor $\beta(\delta)$. Molecular and Cellular Biology 20 5119-5128.

Robinson-Rechavi M, Marchand O, Escriva H, Bardet PL, Zelus D, Hughes S \& Laudet V 2001 Euteleost fish genomes are characterised by expansion of gene families. Genome Research 11 781-788.

Ronquist F \& Huelsenbeck JP 2005 MrBayes 3: Bayesian phylogeny inference under mixed models. Bioinformatics 19 1572-1584.

Rosen ED \& Spiegelman BM 2001 PPAR $\gamma$ : a nuclear regulator of metabolism, differentiation, and growth. Journal of Biological Chemistry 276 37731-37734.

Schmuth M, Haqq CM, Cairns WJ, Holder JC, Dorsam S, Chang S, Lau P, Fowler AJ, Chuang G, Moser AH et al. 2004 Peroxisome proliferator-activated receptor (PPAR) $-\beta / \delta$ stimulates differentiation and lipid accumulation an keratinocytes. Journal of Investigative Dermatology 122 971-983.

Shi Y, Hon M \& Evans RM 2002 The peroxisome proliferator-activated receptor delta, an integer of transcriptional repression \& nuclear receptor signaling. PNAS 99 2613-2618.

Tachibana K, Kobayashi Y, Tanaka T, Tagami M, Sugiyama A, Katayama T, Ueda C, Yamasaki D, Ishimoto K, Sumitomo M et al. 2005 Gene expression profiling of potential peroxisome proliferator-activated receptor (PPAR) target genes in human hepatoblastoma cell lines inducibly expressing different PPAR isoforms. Nuclear Receptor 33.
Tanaka T, Yamamoto J, Iwasaki S, Asaba H, Hamura H, Ikeda Y, Watanabe M, Magoori K, Ioka RX, Tachibana K et al. 2003 Activation of peroxisome proliferator-activated receptor $\delta$ induces fatty acid $\beta$-oxidation in skeletal muscle and attenuates metabolic syndrome. PNAS 100 15924-15929.

Taylor JS, Braasch I, Frickey T, Meyer A \& Van de Peer Y 2003 Genome duplication: a trait shared by 22,000 species of ray-finned fish. Genome Research 13 382-390.

Wang YX, Lee CH, Tiep S, Yu RT, Ham J, Kang H \& Evans RM 2003 Peroxisome-proliferator-activated receptor delta activates fat metabolism to prevent obesity. Cell 113 159-170.

Wolfe KH 2001 Yesterday's polyploids and the mystery of diploidization. Nature Reviews 2 333-341.

Woods IG, Wilson C, Friedlander B, Chang P, Reyes DK, Nix R, Kelly PD, Chu F, Postlethwait JH \& Talbot WS 2005 The zebrafish map defines ancestral vertebrate chromosomes. Genome Research $\mathbf{1 5}$ 1307-1314.

Xu HE, Lambert MH, Montana VG, Parks DJ, Blanchard SG \& Brown PJ 1999 Molecular recognition of fatty acids by peroxisome proliferators-activated receptors. Molecular Cell 3 397-403.

Received in final form 28 November 2006

Accepted 12 December 2006

Made available online as an Accepted Preprint 28 December 2006 